\title{
IISUS ŞI BARABA. UN EPISOD CONTROVERSAT (MT. 27, 15-26; MC. 15, 6-15; LC. 23, 17-25; IN. 18, 38-40)
}

Mihaela GLIGAN*

\begin{abstract}
Jesus and Barabbas. A controversial episode (Mt. 27, 15-26; Mc. 15, 6-15; Lc. 23, 17-25; In. 18, 38-40)' . Barabbas's amnesty, an episode related by all evangelists (Mt. 27, 15-26; Mc. 15, 6-15; Lc. 23, 17-25; In. 18, $38-40)$ is an episode that rised various controversies. It was regarded as a legend or a s Jewish practice, a pplied by the Romans in Jerusa lem, but also as "a public abolition", achieved through people's acclamations.

Origen's writings, "Homilies on Leviticus", or Jerome, "The Homilies of Saint Jerome", interprets the episode in the light of the scapegoat ritual. Barabbas would have act as the scapegoat, therefore, his release would have been equated with the release of the scapegoat from the desert.

Another interpretation is related to the name of Barabbas, which, in Aramaic, means "Son of the Father". Thus, it would be highlighted the antithesis between the true Son of the Fa ther and the other one, who is not wearing His name and who is living his life, as a robber. But this version is less supported by the exegetes, as it will be exposed in the pages of this paper work.

The reason I chose to deal such a theme is my wish to understand the rationality of the crowd who, shortly thereafter, laid the garments on the way of Jesus and met Him with praises, as a king, and after a few days, cried: "Crucify Him! Crucify Him!". At the same time, this character, Barabbas, is an enigma for me: Who was this Barabbas? Why, of the three robbers who were going to be crucified in the same day with Jesus, was chosen Barabbas? Does his name really means "Son of the Father?" I tried to give an answer to all these questions, in my study.
\end{abstract}

Keywords: Barabbas, Jesus, amnesty, scapegoat, Pilate.

“PhD Student, Faculty of Orthodox Teology at „Babeş-Bolyai” University, Cluj-Napoca, Romania.

${ }^{1}$ Publicat sub îndrumarea Pr. Prof. Univ. Dr. Stelian Tofană, care și-a exprimat acordul pentru publicare. 


\section{Introducere}

În jurul lui Baraba s-au conturat în timp multe interpretări. Unii exegeți au privit episodul amnistierii sale ca o legendă, alții ca un obicei practicat cu prilejul unor sărbători. Însă, cea mai atipică interpetare am întâlnit-o în scrierile lui Origen sau ale lui Ieronim, care au tratat episodul în lumina ritualului țapului ispășitor.

Motivul pentru care am ales să scriu despre această temă a fost dorinta de a întelege mai bine cine a fost Baraba. Numele lui înseamnă, într-adevăr, ,fiul tatălui”? Poate fi privit acest episod din perspectiva ritualului țapului ispășitor? A existat, într-adevăr, obiceiul de a elibera un deținutcu ocazia sărbătorii Paștilor? La acesteîntrebări voi încerca să dau un răspuns în continuare.

\section{Semnificaţia numelui „Baraba”}

Majoritatea dicţionarelor pe care le-am studiat cu privire la semnificația numelui „Baraba”, amintesc detaliile din evanghelii. Astfel, Baraba a fost ,un tâlhar, arestat pentru omor şi terorism politic, (...) un exemplu al efectelor jertfei de ispăşire înlocuitoare" ${ }^{2}$, ,un iudeu periculos, căpetenie de răzvrătiţi”’3.

În aramaică, Bar-abba înseamnă ,fiul tatălui,” adică al învățătorului. În vremea Mântuitorului, „Abba” a fost probabil un titlu onorific (Mt. 23, 9-10), dar mai târziu a devenit un nume propriu-zis ${ }^{4}$. Varianta ,bar-rabba,” găsită în Harklean Syriac, ar însemna ,fiu al rabinului sau al profesorului", fapt care ar sugera că Barabba era fiul unui rabin sau a fost un nume pur convențional, care nua însemnat ceva. Nimic altceva nu este cunoscut despre $\mathrm{l}^{5}$.

2 J. Douglas, Dicţionar biblic, trad. Liviu Pop, John Tipei, Oradea, Edit. Cartea Creştină, 1995, p. 149.

${ }^{3}$ Ioan MIRCEA, Dicţionar al Noului Testament, Bucureşti, EIBMBOR, 1995, p. 54.

${ }^{4}$ Daniel G. Reid consideră că forma $A b b \bar{a} h$, atestată ca nume de persoană, datează din vremea lui Iisus, iar dacă acel om a avut un fiu, în greceşte el ar fi fost numit Barbabbas. Daniel G. ReID, Dicţionarul Noului Testament, trad. Lucian Ciupe, Timotei Manta, Oradea, Edit. Casa Cărţii, 2008, p. 1140.

5 James ORR, The International standard Bible encyclopedia, vol. 1, Chicago, The Howard-Severance Co., 1915, p. 402. 
Această lipsă de informaţii a stârnit, în timp, numeroase întrebări. O primă întrebare este legată de numele personajului: Isus Baraba este versiunea originală a versetului mateian? Cei care răspund negativ la această întrebare accentuează tendinţa generaţiilor de mai târziu de a da un nume celor care nu aveau unul, în relatările Noului Testament. Un alt argument adus de opozanţi este versetul 17: „,(Isus) Baraba sau Iisus care Se numeşte Hristos?", verset care ar putea reflecta intervenţia unui copist a cărui intenţie a fost să sublinieze paralelismul celor două personalităţi pe care Pilat le are în faţă.

Dar, dacă numele Isus a apărut în textul original al lui Matei, din ce motiv l-au omis copiştii de mai târziu, astfelîncât este absent din multe manuscrise importante?

S-a sugeratcă la baza exciziei deliberate a fost un raţionament teologic. Origen avea o atitudine defensivă cu privire la acest verset, susţinând că nu este potrivit ca numele lui Iisus să fie dat unui criminal şi, astfel, acest nume ar fi fost adăugat de eretici. $\mathrm{O}$ astfel de atitudine, i-a influenţat, probabil, pe copiştii creștini de mai târziu, care nu au mai adăugat, „Isus” la numele lui Baraba sau 1-au şters ca pe o impietate dacă acesta apărea deja.

Conform lui Cohn, Rigg, Maccoby şi S.L. Davies, iniţial, în faţa lui Pilat ar fi fost o singură persoană, lisus din Nazaret. Prin urmare, Baraba nu era o persoană, ci unalt aspectal identităţii lui Iisus, folosit pentru o acuzaţie religioasă. De exemplu, pentru acuzaţia religioasă, Iisus ar fi fost numit Baraba, ,fiul Tatălui”, iar pentru acuzaţia politică, regele iudeilor. Mergând mai departe, adepţii acestei interpretări consideră că Pilat l-ar fi condamnat pe Iisus pentru acuzaţia politică, căci Baraba sau acuzaţia religioasă, nu era de competenţa romană.În ceea ce priveşte intenţia evanghelistului de a-1 prezenta pe Baraba drept o persoană distinctă de Iisus, adepţii care susţin interpretarea amintită ulterior consideră că Matei a făcut aceasta fie din confuzie, fie dintr-o stratagemă anti-evreiască, transformând simpatia mulţimii pentru Baraba într-o condamnare faţă de Iisus.

Dar această perspectivă fantastică nu rezistă în faţa analizei critice şi în faţa unui raţionament logic. Dacă Baraba ar fi fost un alt titlu pentru Iisus, atunci adversarii săi ar fi trebui să îl acuze şi să îşi dorească să îl ucidă sub aspectul lui Baraba, potrivit versetului ,,pentru aceasta căutau şi mai mult iudeii să-L omoare, (...) pentru că zicea că Dumnezeu este Tatăl Său” (In. 5, 18). 
O interpretare la fel de surprinzătoare se inspiră din dovezile lui Filon care descriu evenimentele din preajma vizitei regelui Irod Agripa I la Alexandria, în anul 38 d. Hr. În aceste evenimente este descrisă atitudinea manifestanţilor anti-evrei de la Alexandria care, având cunoştinţă despre vizita regelui Irod, şi-au exprimat dispreţul prin intermediul unui lunatic pe nume Karabas, care a fost ţinta multor glume, întrucât hoinărea dezbrăcat prin oraş. Manifestanţii 1-au îmbrăcat cu un veşmânt dintr-o pătură, i-au pus o diademă în batjocură şi i-au dat un sceptru din trestie de papirus, după care 1-au salutat ca pe un rege. S. Reinach afirmă că numele acestui personaj, relatat de Filon, a fost transformat de către evanghelişti în Baraba.

Spre deosebire de aceste interpretări, Bajsić leagă imaginea lui Baraba de cea a lui Pilat. Potrivit acestei teorii, Pilat încearcă să evite eliberarea lui Baraba, ştiind că mulţimea îl vrea eliberat. Pentru a evita aceasta, guvernatorul îl oferă mulţimii pe Iisus, care era inofensiv din punct de vedere politic, pentru a scăpa de Baraba. Insă, această interpretare este contrară scrierilor evanghelice ${ }^{6}$.

\section{2. „Baraba” în scrierile primilor creştini}

Scrierile Bisericii primare sunt aproape lipsite de speculaţii asupra biografiei lui Baraba şi a acţiunilor sale ulterioare. O excepţie este găsită în Ethiopic book of the Cock şi în Martiriul lui Pilat.

Potrivit primei cărţi, Pilat, confruntat cu mulţimea care cerea eliberarea lui Baraba, a fost obligat să aprobe crucificarea lui Iisus. După ce soldaţii 1-au batjocorit pe Hristos, 1-au forțat să Îşi poarte crucea până la Ėdomāq, la est de Ierusalim. După aceea, Simon din Cyrene Îl ajută pe Iisus şi îi poartă crucea pe Golgota, unde se întâlnesc cu Barabbas, care urmează să fie eliberat, şi cu alţi doi criminali condamnaţi la crucificare.

Martiriul lui Pilat sugerează că Baraba şi soţia lui Iuda au fost fraţi, amândoi arătând aceeaşi iubire pentru bani. Între scriitorii creştini care au scris despre Baraba se numără Origen, Ieronim, Iustin Martirul, toţi interpretând episodul în lumina ritualului ţapului ispăşitor. Astfel, în lucrarea Omilii la Levitic, Origen menţionează că Iisus Îşi asumă rolul

${ }^{6}$ Raymond E. Brown, Moartea lui Mesia din Ghetsimani până la mormânt, vol. I, trad. Marius Bitiuşcă, Iaşi, Edit. Sapientia, 2012, p. 753, 766-768. 
ţapului de jertfă, care trebuie oferit Domnului ca ofrandă pentru ispăşirea păcatelor, iar lui Baraba i se atribuie rolul ţapului ispăşitor .

Eliberarea lui Baraba este echivalată cu eliberarea țapului ispăşitor în deşert. Un alt element sacerdotal, găsit în interpretarea lui Origen, este reprezentarea lui Pilat ca slujitor cultic. Nu este clar dacă Pilat trebuie înţeles ca un mare preot responsabil de selecţia caprelor sau dacă el este înţeles doar ca cel care duce ţapul ispăşitor în pustie. Spălarea mâinilor se poate referi fie la spălarea făcută de marele preot după punerea mâinilor peste ţapul ispăşitor, fie la cel care a însoţit animalul în deşert.

În Omilia 93, Ieronim transmite o interpretare similară a episodului, comparându-L pe Iisus cu ţapul de jertfă şi pe Baraba cu ţapul ispăşitor. Spre deosebire de cei doi autori menţionaţi anterior, Iustin Martirul şi Tertulian Îl identifică pe Hristos cu ambele animale, atât cu ţapul de jertfă, cât şi cu cel salvator. Potrivit lui Iustin, ţapul ispăşitor prefigurează batjocorirea şi moartea Mântuitorului povocată de iudei, iar ţapul de jertfă Parusia .

O perspectivă contemporană care merge pe aceeaşi linie de interpretare este suţinută de Wratislaw. Daniel Stökl Ben Ezra, rezumând argumentul lui Wratislaw, subliniază cinci puncte conceptuale:

- Sunt prezentate două,,victime” (Iisus şi Baraba) tatălui”)

- Prezintă asemănări între ele (ambele sunt numite ,Iisus” şi ,fiul

- Simbolizează puterile opuse

- Există o alegere: cine să fie eliberat şi cine să fie ucis

- Se pronunţă o mărturisire (,,Sângele Lui asupra noastră”)

În ceea ce priveşte versetele 24-25 din Evanghelia după Matei, comentatorii identifică spălarea mâinilor şi declaraţia de nevinovăţie a lui Pilat: „nevinovat sunt de sângele Dreptului acestuia” (Mt. 27, 24) cu ritualul din Deut. 21, 1-9.

Împotriva interpretării se ridică anumite obiecţii. Ritualul din Deuteronom este folosit de comunitate pentru a-şi declara nevinovăţia, atunci când identitatea unui criminal este necunoscută, aşa cum reiese din Deut. 21, 1. Cu siguranţă, nu aceeaşi situaţie este descrisă în pasajul mateian, întrucât nu a murit nimeni încă, iar vinovatul este cunoscut (Mt. $27,25)$. 


\section{3. Amnistierea lui Baraba - un obicei controversat?}

Şi episodul amnistierii a ridicat numeroase critici. P. Winter consideră că oferta lui Pilat adresată mulţimii, de a alege între două persoane, este în contrazicere cu prerogativa poporului de a-şi manifesta liber voinţa pentru o singură persoană, care ar fi beneficiat de eliberare. Această contradicţie este completată de imposibilitatea morală pentru sinedrişti de a convinge mulţimea să ceară eliberarea unui tâlhar.

Potrivit altora, amnistierea lui Baraba ${ }^{7}$ de către Pilat a fost un fapt real, însă a avut loc mai târziu decât în momentul procesului lui Iisus, aceste două evenimente, întâmplate la date diferite, fiind după aceea combinate de evanghelişti şi de tradiţia creştină într-unul singur ${ }^{8}$.

Pe de altă parte, romanii aveau obiceiul să amnistieze pe anumiți infractori cu ocazia unor sărbători, a unor victorii sau prin hotărârea Senatului. În Grecia exista un obicei de eliberare a prizonierilor cu ocazia anumitor sărbători religioase: sărbătoarea Dionysiei, în onoarea zeului Dionysus Eleuthereus sau eliberarea temporară a sclavilor cu ocazia festivalului Kronia?.

O altă teorie cu privire la obiceiul amnistierii se referă la practicile comune ale oficialilor imperiali. În corespondenţa cu împăratul Traian, Pliniu menţionează că: ,prin ordinul proconsulilor şi legaţilor, răufăcătorii condamnaţi care fuseseră amestecaţi cu sclavii pentru a lucra în serviciul public, au fost eliberaţi; Traian voia ca acest abuz să fie corectat insistând că sentinţa putea fi anulată doar de autoritatea competentă" ${ }^{\prime 10}$. Însă, afirmă Raymond Brown, toate aceste exemple sunt

${ }^{7}$ În opinia lui Rigg, Iisus a fost adus în faţa lui Pilat de două ori, mai întâi ca Iisus Barrabas (,fiul Tatălui”) şi apoi ca Iisus numit Hristos. În prima instanţă, Iisus fiind găsit nevinovat în temeiul legii romane, a fost eliberat. Dar ca Hristos, în a doua şedinţă de judecată, a fost găsit vinovat pentru crimă de înaltă trădare. Astfel, Rigg concluzionează că nu a existat niciun obicei de eliberare a unui prizonier cu ocazia Paştilor, ci mai degrabă a existat un caz în care o persoană a fost acuzată de două ori. Robert L. MerRITT, ,Jesus Barabbas and the paschal pardon”, în Journal of Biblical Literature, vol. 104, The Society of Biblical Literature, 1985, p. 58.

${ }^{8}$ Ioan Fruma, Procesul lui Iisus în lumina noilor documente şi descoperiri arheologice, Bucureşti, Edit. Roza Vânturilor, 2000, p. 294.

${ }^{9}$ Robert L. MERRITT, „Jesus Barabbas and the paschal pardon”, p. 62-63.

${ }^{10}$ Raymond E. Brown, Moartea lui Mesia din Ghetsimani până la mormânt, p. 770. 
cazuri izolate de comportament uman sau graţieri în masă cu motive diferite şi nu spun nimic despre un obicei regulat de sărbătoare.

Unii comentatori au afirmat că eliberarea unui prizonier cu ocazia sărbătorii Paştilor a fost doar continuarea unui vechi obicei ebraic, inagurat pentru comemorarea ieşirii din robia Egiptului. Dacă acest argument ar fi fost adevărat, secţiunile din Talmud care descriau sărbătoarea Paştilor trebuiau să amintească despre acest obicei, dar nu există nicio referință la acesta ${ }^{11}$.

În cartea sa, Ioan Fruma, referindu-se la acest obicei, afirmă: „În privinţa obiceiului aplicat de Pilat, nu poate fi vorba decât de posibilitatea pentru judecătorul roman de a stinge procesul sau, după opinia lui Mayr, eventual acordarea amnistiei în baza unui mandat special al Cezarului ${ }^{12}(. .$.$) Însă procesele pentru crimen maiestatis erau exceptate de$ la aceste aboliri sau amnistii" ${ }^{13}$. Legea romană permitea două tipuri de amistiere: indulgentia, iertarea unui condamnat, şi abolitio, achitarea unei persoane înainte de a fi judecată ${ }^{14}$.

În procesul din faţa lui Pilat, soarta lui Iisus a depins de oferta guvernatorului roman făcută mulţimii. Pentru Pilat, această alternativă a reprezentat realizarea intenţiei sale de condamnare a lui Baraba. Totodată, alternativa ascundea şi eschivarea sa de a hotărî singur eliberarea lui Iisus, nădăjduind să justifice această măsură prin verdictul poporului.

Pentru acuzatori, alternativa propusă de Pilat a fost o surpriză, dar şi un îndemn să procedeze imediat la convingerea mulţimii în favoarea dorinţei lor.

${ }^{11}$ Pilat ar fi urmat acest obicei vechi pentru a-şi satisface supuşii. Richard WELLINGTON, „The pardoning of prisoners by Pilate”, în The American Journal of Theology, vol. 21, The University of Chicago Press, 1917, p. 110-111.

${ }^{12}$ Un document care sprijină autenticitatea scenei cu Baraba este Papirusul Florentin $n r$. 61, în care este prezentat un proces-verbal al unei dezbateri judecătoreşti din anul 85 d. Hr., sub prezidiul guvernatorului C. Septimius Vegetus care, în urma cererii poporului, eliberează un arestat cu numele Phibion. De aici se deduce că guvernatorii provinciilor romane aveau un mandat special al Cezarului pentru a elibera, la cererea mulţimii, pe cei supuşi jurisdicţiei lor. Ioan Fruma, Grigorie T. MARCU, Procesul Mântuitorului. Studiu juridic şi teologic, Sibiu, Edit. Andreiană, 2017, p. 172.

${ }^{13}$ Ibidem, p. 171-172.

${ }^{14}$ Craig S. KeEner, Comentariu cultural-istoric al Noului Testament, trad. Silviu Tatu, Raluca Mirăuţă, Teofil Stanciu, Luca Creţan, Dorin Axente, Timeia Pop, Oradea, Edit. Casa Cărţii, 2018, p. 365. 
Pentru mulţimea prezentă, oferta guvernatorului echivala cu primirea dreptului de a decide eliberarea lui Iisus sau a lui Baraba ${ }^{15}$.

Sunt de remarcat cuvintele rostite de Pilat: ,eu nu găsesc în El nici o vină" ${ }^{16}($ In. 18,38$)$ cuvinte prin care, fără să ştie, împlineşte una dintre profeţiile mesianice: ,nu săvârşise nici o nedreptate şi nici înşelăciune nu fusese în gura Lui” (Is. 53, 9).

Procuratorul nu cere acordarea acestui ,har în favoarea sărbătorii’” pentru un vinovat vrednic de moarte, ci subliniază ideea nevinovăției lui Iisus, sperând că mulţimea va prefera un inocent şi nu un ,tâlhar."' Însăşi întrebarea ironică: ,,Voiţi deci să vă eliberez pe regele iudeilor?"' (In. 19, 39), menită ,,să abată prin ridiculizare furia mulţimii" ${ }^{17}$, susţine reacţia la care se aştepta Pilat.

\section{Concluzii}

Dincolo de toate interpretările cu privire la Baraba, se întâlneşte un fapt care nu lasă loc de îndoieli: imaginea pe care iudeii şi-au format-o despre Mesia. Purtând în suflet amintirea regatului davidic, iudeii aşteptau un nou David şi, indiferent dacă este rege, mare preot sau profet, Mesia devine purtătorul speranțelor poporului. La un moment dat, dorinţa de a-1 vedea pe Mesia a devenit atât de arzătoare încât orice prooroc era privit ca fiind Cel ce trebuia să vină, aşa cum a fost şi în cazul lui Ioan Botezătorul, când toţi se întrebau în ,,inimile lor”: „,Nu cumva el este Hristosul?" (Lc. 3, 15) ${ }^{18}$.

La fel s-a întâmplat şi în cazul lui Iisus, până în momentul în care imaginea distorsionată a iudeilor cu privire la Mesia nu mai concorda cu mesajul Celui care ,,a venit să împlinească” Legea (Mt. 5, 17). Privit prin

${ }^{15}$ Ioan Fruma, Procesul lui Iisus în lumina noilor documente şi descoperiri arheologice, p. 292.

${ }^{16}$ Judecătorii îşi exprimau verdictul în formele: Absolvo (nevinovat), Condemno (vinovat) şi Non liquet (îndoielnic). Septimus Buss, The trial of Jesus illustrated from Talmud and roman law, Londra, S.P.C.K., 1906, p. 113-114.

${ }^{17}$ Teofilact, Comentar la Evanghelia de la Ioan, Oradea, Edit. Pelerinul Român, 1998, p. 762 .

${ }^{18}$ Cezar-Paul HÂrlăoAnu, „Evoluţia ideii mesianice în gândirea rabinică”, în Anale Teologie-Iaşi, disponibil la: http://www.analeteologie-iasi.ro/arh/2005/11.pdf, (accesat la 4.07.2019). 
această prismă, Iisus din Nazaret nu putea fi Mesia cel aşteptat şi dorit de popor, iar în faţa acestei dezamăgiri alegerea lui Baraba care ar fi putut printr-o răscoală să le ofere îndeplinirea dorinţei de a scăpa de sub ocupaţia romană ${ }^{19}$ a fost mai tentantă.

\section{Referinţe bibliografice:}

1. Brown, Raymond E., Moartea lui Mesia din Ghetsimani până la mormânt, vol. I, trad. Marius Bitiuşcă, Iaşi, Edit. Sapientia, 2012;

2. Buss, Septimus, The trial of Jesus illustrated from Talmud and roman law, S.P.C.K., Londra, 1906;

3. Douglas, J., Dicţionar biblic, trad.Liviu Pop, John Tipei, Oradea, Edit. Cartea Creştină, 1995;

4. FRUMA, Ioan, Procesul lui Iisus în lumina noilor documente şi descoperiri arheologice, Bucureşti, Edit. Roza Vânturilor, 2000;

5. Fruma, Ioan, Marcu, Grigorie T., Procesul Mântuitorului. Studiu juridic şi teologic, Sibiu, Edit. Andreiană, 2017;

6. HÂRLĂOANU, Cezar-Paul, „Evoluţia ideii mesianice în gândirea rabinică", în Anale Teologie-Iaşi, disponibil la: http://www.analeteologie-iasi.ro/arh/2005/11.pdf, (a ccesat la 4.07.2019);

7. JUSTIN MARTYR, The dialogue with Trypho, Londra, The Macmillan Co, 1930;

8. KeEnER, Craig S., Comentariu cultural-istoric al Noului Testament, trad. Silviu Tatu, Raluca Mirăuţă, Teofil Stanciu, Luca Creţan, Dorin Axente, Timeia Pop, Oradea, Edit. Casa Cărţii, 2018;

9. MACLEAN, Jennifer K. Berenson, „Barabbas, the Scapegoat Ritual, and the Development of the Passion Narrative", în The Harvard Theological Review, vol. 100, Cambridge University Press, 2007;

10. MERRITT, Robert L., „Jesus Barabbas and the paschal pardon”, în Joumal of Biblical Literature, vol. 104, The Society of Biblical Literature, 1985;

11. MirCEA, Ioan, Dicţionar al Noului Testament, Bucureşti, EIBMBOR, 1995;

12. ORIGEN, Omilii şi adnotări la Levitic, trad. Adrian Muraru, Iaşi, Edit. Polirom, 2006;

${ }^{19}$ Gheorghios Patronas, Parcursul istoric al lui Iisus - de la iesle la mormântul gol, trad. Sabin Preda, Bucureşti, Edit. Bizantină, 2011, p. 373. 
13. ORLOV, Andrei A., The atoning dyad: The two goats of Yom Kippur in the Apocalypse of Abraham, Leiden, Brill Publishers, 2016;

14. ORR, James, The International standard Bible encyclopedia, (1 vol.), Chicago, The Howard-Severance Co., 1915;

15. PAtronos, Gheorghios, Parcursul istoric al lui Iisus - de la iesle la mormântul gol, trad. Sabin Preda, Bucureşti, Edit. Bizantină, 2011;

16. PiOvANELLI, Pierluigi, „Exploring the Ethiopic Book of the Cock, an apocryphal Passion Gospel from Late Antiquity", în HTR, vol. 96, Cambridge University Press, 2003;

17. REID, Daniel G, Dicţionarul Noului Testament, trad. Lucian Ciupe, Timotei Manta, Ora dea, Edit. Casa Cărţii, 2008;

18. TeOfilact, Comentar la Evanghelia de la Ioan, Oradea, Edit. Pelerinul Român, 1998;

19. WeLlington, Richard, „The pardoning of prisoners by Pilate”, în The American Journal of Theology, vol. 21, The University of Chicago Press, 1917. 